\title{
Evaluation of the Anti-LipL32 Monoclonal Antibodies Potential for Use in Leptospirosis Immunodiagnostic Tests
}

\author{
M. L. Coutinho, F. A. Vasconcellos, C. P. H. Fernandes, \\ N. Seyffert and F. K. Seixas \\ Center for Biotechnology, Federal University of Pelotas, Rio Grande do \\ Sul, Brazil \\ A. I. Ko \\ Centro de Pesquisa Gonçalo Moniz, Fundação Oswaldo Cruz, Salvador, \\ BA, Brasil

\section{O. A. Dellagostin and J. A. G. Aleixo} \\ Center for Biotechnology, Federal University of Pelotas, Rio Grande do \\ Sul, Brazil
}

\begin{abstract}
LipL32 is the major lipoprotein in the membrane of pathogenic leptospira. In this work, we report on the production of monoclonal antibodies (MAbs) against recombinant LipL32 (rLipL32) and on the evaluation of their potential for use as reagents in diagnostic tests for leptospirosis. The MAbs were all of the $\operatorname{IgG}_{2 b}$ isotype and reacted specifically with native LipL32 in pathogenic serovars only. MAbs reacted in the same region of the rLipL32 molecule and their affinity constant was between $5 \times 10^{7} \mathrm{M}^{-1}$ and $6 \times 10^{6} \mathrm{M}^{-1}$. These results suggest that although the MAbs cannot be used together, they are well suited for diagnostic tests of leptospirosis based on LipL32 detection.
\end{abstract}

Keywords: Leptospira, Recombinant antigens, Antibody affinity, Epitope mapping, ELISA, Western blotting

Address correspondence to J. A. G. Aleixo, Center for Biotechnology, Federal University of Pelotas, Rio Grande do Sul, Brazil. E-mail: biotjaga@ufpel.edu.br 


\section{INTRODUCTION}

Leptospirosis is an important zoonotic disease that occurs in endemic form throughout the world. The infection is caused by different serovars of the bacteria Leptospira interrogans sensu lato whose natural reservoirs are wild and domestic animals. Humans contract the disease by exposure to urine or tissues from infected animals or from contaminated water, which is commonplace in regions frequently subjected to floods and lacking proper sanitation, e.g., urban slums or rural areas. ${ }^{[1]}$

Leptospirosis clinical signs in humans, especially in the acute phase, can be easily mistaken with the symptoms of diverse feverish diseases such as common influenza, malaria, dengue, aseptic meningitis, and brucelosis. Thus, it is difficult to establish a clinical diagnosis and the confirmation of the disease generally relies on serological tests that demonstrate serum conversion. ${ }^{[2]}$

There are several reports of tests for confirming clinical diagnosis of leptospirosis either for humans ${ }^{[3-5]}$ or animals, ${ }^{[6,7]}$ all lacking in sensitivity in the acute phase of the illness. The microscopic agglutination test (MAT) is the serological test of choice for diagnosis of leptospirosis but, besides having low sensitivity in the initial phase of the illness, it is labor intensive, since requires the maintenance of a large number of live serovars in the laboratory. The low sensitivity of MAT is due to the fact that the immune systems of individuals take $8-10$ days to produce detectable levels of antibodies against infective agents. ${ }^{[8]}$

Most of the tests currently available for the detection of anti-leptospiral antibodies utilize antigens which are heat-extracted from the saprophytic serovar Patoc or from a specific pathogenic strain. These tests present the drawback of being useful only if the infection is caused by the same or related serovar used as antigen, since the immune response elicited by LPS, an important Leptospira immunogen, is serovar specific.

In recent years, using serum from infected patients, LipL32 was identified as the major lipoprotein of the Leptospira outer membrane and has been considered an important target for the development of diagnostic tests, since it is a protein conserved among pathogenic serovars. ${ }^{[9]}$ In this study, we report on the production of monoclonal antibodies (MAbs) against recombinant LipL32 (rLipL32) and on MAb characterization with respect to important features they should have in order to be used as reagents in immunological tests for the diagnosis of leptospirosis.

\section{EXPERIMENTAL}

\section{Leptospiral Strains and Culture Conditions}

Leptospira interrogans serovar Copenhageni strain Fiocruz L1 130 was obtained from the Oswaldo Cruz Foundation (FIOCRUZ) and the other 
leptospiral serovars were from the culture collection maintained at the Centro de Controle de Zoonoses, Universidade Federal de Pelotas. The bacteria were cultivated in EMJH medium for 7 days at $30^{\circ} \mathrm{C}$, centrifuged at $18,000 \mathrm{~g}$, suspended in phosphate buffered saline (PBS, $0,05 \mathrm{M}, \mathrm{pH} 7,4)$ to a concentration of $2 \times 10^{8}$ leptospires $\mathrm{mL}^{-1}$ and heat inactivated overnight at $56^{\circ} \mathrm{C}$.

\section{Production of Recombinant LipL32}

The lipL32 gene, obtained by PCR using the DNA from L. interrogans L1 130 as template, was cloned into the pAE expression vector ${ }^{[10]}$ that allows fusion of the protein with a $6 \times$ His tag, resulting in the plasmid named pAE/lipL32. This plasmid was used to transform E. coli BL21(DE3) pLysS, which was cultivated in liquid medium containing ampicillin. When the absorbance at $600 \mathrm{~nm}$ reached 0.8, isopropyl-1-thio- $\beta$-D-galactoside (IPTG) was added to a final concentration of $1 \mathrm{mM}$ and the cells were harvested by centrifugation $3 \mathrm{~h}$ later. After centrifugation at $10,000 \times \mathrm{g}$ for 5 minutes at $4{ }^{\circ} \mathrm{C}$, the cells were lysed by sonication, centrifuged once more and the supernatant was submitted to protein purification by affinity chromatography in a nickel charged Sepharose column using the ÄKTAPrime chromatography system (Amersham Biosciences, USA). Fractions containing rLipL32 were dialyzed against PBS and glycine $0.1 \%, \mathrm{pH} 8.0$, for approximately $16 \mathrm{~h}$ at $4{ }^{\circ} \mathrm{C}$. Protein in the final preparation was analyzed by $15 \%$ SDS-PAGE and quantified by the Bradford method. ${ }^{[11]}$

\section{MAbs Production}

Procedures for production of MAbs were as described previously. ${ }^{[12]}$ Sixweek-old female BALB/c mice were injected intraperitoneally on day 1 with $75 \mu \mathrm{g}$ of $\mathrm{rLipL} 32$ prepared 1:1 with sterile PBS and Freund's complete adjuvant. Injections were repeated on days 14, 21, and 28 using Freund́s incomplete adjuvant. Immunization efficiency was verified by indirect ELISA five days before fusion and mice showing the highest antirLipL32 titer received a final booster injection. Splenocytes were removed and fused to Sp2/O myeloma cells in the presence of PEG 1450. Hybridomas were selected under HAT medium and positive wells were identified using indirect ELISA with rLipL32 as capture antigen. The cells from wells presenting good antibody activity were cloned twice by the limiting dilution technique, retested, and cultivated for freezing in liquid nitrogen or injecting in mice previously primed with pristane for ascites production. MAbs were purified from ascitic fluid using a protein A-Sepharose 4B column according to the manufacturer instructions (GE Healthcare, Piscataway, NJ, USA), dialyzed against PBS and concentrated with PEG 20000. 
Concentration of purified MAbs was determined at $280 \mathrm{~nm}$, standardized to $5 \mathrm{mg} \mathrm{mL}^{-1}$ with PBS and the preparations were stored at $-20^{\circ} \mathrm{C}$ until use.

\section{Determination of MAb Isotype and Specificity}

MAbs isotypes were determined with specific anti-isotype sera commercially available (Sigma-Aldrich, St Louis, MO). For determination of specificity heat-inactivated leptospiral cultures $\left(2.5 \times 10^{7}\right.$ leptospires well $\left.{ }^{-1}\right)$ were added to microtitre plate wells which were previously coated with a 1:10 dilution of poly-L-lysine and incubated for $1 \mathrm{~h}$ at $37^{\circ} \mathrm{C}$. The wells were washed three times with PBST (PBS plus 0,05\% Tween 20) and purified MAbs diluted 1:1000 in PBST were added and left to react for $1 \mathrm{~h}$ at $37^{\circ} \mathrm{C}$. The washing was repeated and a goat anti-mouse peroxidase conjugate was added and incubated for another $1 \mathrm{~h}$ at $37^{\circ} \mathrm{C}$. Wells were washed five times with PBST and the presence of the antigen-antibody complex was revealed with a substrate/chromogen solution containing OPD $(0.4 \mathrm{mg} / \mathrm{mL}$ in $0.1 \mathrm{M}$ citrate buffer, $\mathrm{pH} 5.0$ ) and $0,03 \%$ hydrogen peroxide. Color development was measured at $450 \mathrm{~nm}$ in an ELISA reader (Multiskan MCC/340, Titertek Instruments, Huntsville, AL, USA).

\section{Western Blot Analysis}

Samples from sonicated leptospiral strains were separated by SDS-PAGE using a $12 \%$ gel and a discontinuous buffer system. ${ }^{[13]}$ After electrophoresis, proteins were transferred onto PVDF membranes for testing specific LipL32 detection by MAbs. Membranes were blocked with 5\% non-fat dry milk diluted in PBS and reacted with 1:1,000 dilutions of MAbs preparations. After washing, the membrane was incubated with a goat anti-mouse Ighorseradish peroxidase conjugate (Sigma) and bands were visualized with a chemiluminiscence detection system (Amershan, UK).

\section{Affinity Constants}

Mabs functional affinity constants (Ka) for rLipL32 were determined by the ELISA method. ${ }^{[14]}$ Briefly, concentrations of the antigen varying from $2.0 \times 10^{-7} \mathrm{M}$ to $1.8 \times 10^{-9} \mathrm{M}$ were incubated in solution with known amounts of each Mab until equilibrium was reached $\left(16 \mathrm{~h}\right.$ at $\left.30^{\circ} \mathrm{C}\right)$. After incubation, unbound antibodies in the liquid phase were determined by indirect ELISA using microtiter plate wells coated with rLipL32 $(2 \mathrm{mg} / \mathrm{mL})$ and goat anti-mouse Ig-peroxidase conjugate. The optical densities (OD) were read at $450 \mathrm{~nm}$ and graphics were built according to Bobrovnik. ${ }^{[15]}$ The linear relationships between values $\left(A_{0}-A_{i}\right) / A_{i}$ and $l_{i}$ (where $A_{0}$ is the OD 
of Mab without reacting with antigen, $A_{i}$ is the OD of Mab after reacting with each antigen concentration and $l_{i}$ is the antigen concentration) were determined and the values of functional Ka were defined by the slope of these linear relationships.

\section{Additivity Index}

To group MAbs according the region of the antigen to which each one reacts, additivity index (AI) determination was performed as described by Friguet et al. ${ }^{[16]}$ An indirect ELISA was performed using paired MAbs and each MAb alone in a well at saturation levels in a plate coated with LipL32 $(2 \mu \mathrm{g} / \mathrm{mL})$. The amount of bound antibody was tested by adding goat antimouse Ig-peroxidase conjugated antibody. An additivity index for each pair of MAbs binding to epitopes of the antigen molecule fixed in ELISA plates was calculated according to the formula $\left\{\left[2 \mathrm{~A}_{1+2} /\left(\mathrm{A}_{1}+\mathrm{A}_{2}\right)\right]-1\right\} \times 100$, where $\mathrm{A} 1, \mathrm{~A} 2$, and $\mathrm{A} 1+2$ are absorbance values with MAb 1 alone, MAb 2 alone, and the two MAbs together, respectively. AI values close to zero suggest that the antibodies tested recognize the same or closely associated epitopes, while AI higher than 50\% suggest simultaneous binding of antibodies to distinct epitopes. ${ }^{[15]}$

\section{RESULTS AND DISCUSSION}

\section{Monoclonal Antibodies Production, Isotyping, and Specificity}

As a result of one fusion experiment, six MAbs against LipL32 were produced and they were all from the same isotype $\left(\mathrm{IgG}_{2 \mathrm{~b}}\right)$. The MAbs were evaluated in an indirect ELISA with different pathogenic and saprophytic leptospiral serovars in order to identify if they react specifically with native LipL32. All six MAbs have shown good reactivity with the pathogenic serovars tested and no reaction was observed when the MAbs were reacted with saprophytic serovars (Table 1). Western blot analysis was used to confirm the ELISA results and to verify if the epitope the MAb react with is linear or conformational (Figure 1).

LipL32 is a lipoprotein only expressed on the surface of pathogenic leptospires and here we have shown that the MAbs react with all pathogenic leptospiral strains tested in ELISA and produced a clear band at $32 \mathrm{kDa}$ in the Western blot, while no reactions were observed with the saprophytic serovar patoc. There are already a few reports on the production of MAbs against leptospira, but they were raised against a specific serovar and cross-reacted with only a few serovars from the same or related serogroups. ${ }^{[6,7]}$ 
Table 1 . Reactivity of MAbs with different leptospiral serovars in indirect ELISA

\begin{tabular}{|c|c|c|c|c|c|c|c|}
\hline \multirow{2}{*}{ 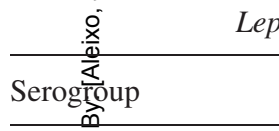 } & eptospira & \multicolumn{6}{|c|}{ Monoclonal antibodies } \\
\hline & Serovar & LipL2 & LipL3 & LipL4 & LipL5 & LipL6 & LipL7 \\
\hline \multirow{4}{*}{ 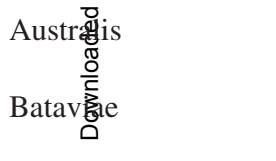 } & Australis & $+^{a}$ & + & + & + & + & + \\
\hline & Bratislava & + & + & + & + & + & + \\
\hline & Bataviae & + & + & + & + & + & + \\
\hline & Brasiliensis & + & + & + & + & + & + \\
\hline Hebdomadis & Hebdomadis & + & + & + & + & + & + \\
\hline \multirow[t]{2}{*}{ Icterohaemorrhagiae } & Copenhageni & + & + & + & + & + & + \\
\hline & Icterohaemorrhagiae & + & + & + & + & + & + \\
\hline Pomona & Pomona & + & + & + & + & + & + \\
\hline Pyrogenes & Pyrogenes & + & + & + & + & + & + \\
\hline \multirow[t]{2}{*}{ Sejroe } & Hardjo & + & + & + & + & + & + \\
\hline & Wolffi & + & + & + & + & + & + \\
\hline Cynopteri & Cynopteri & + & + & + & + & + & + \\
\hline Ballum & Ballum & + & + & + & + & + & + \\
\hline Whitcombi & Celledoni & + & + & + & + & + & + \\
\hline Javanica & Javanica & + & + & + & + & + & + \\
\hline Tarassovi & Tarassovi & + & + & + & + & + & + \\
\hline Shermani & Shermani & + & + & + & + & + & + \\
\hline Panama & Panama & + & + & + & + & + & + \\
\hline Andamana & Andamana & - & - & - & - & - & - \\
\hline Semaranga & Patoc & - & - & - & - & - & - \\
\hline
\end{tabular}

${ }^{a}$ Positive reaction $=\mathrm{OD}$ values $2 \mathrm{X}$ or greater than $\mathrm{OD}$ of serovar Patoc. 


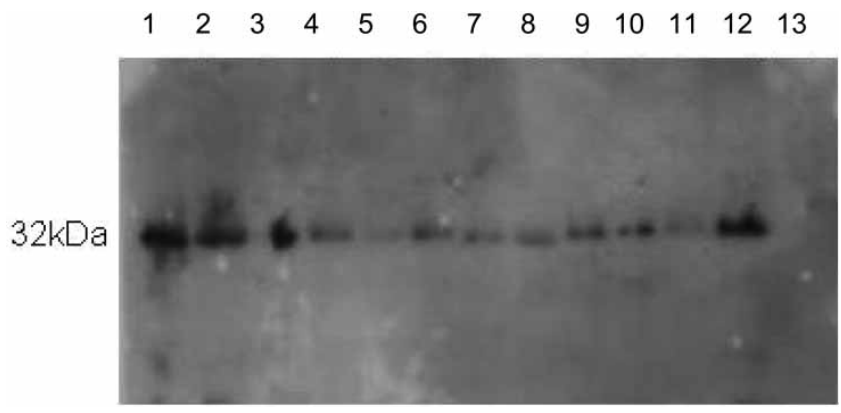

Figure 1. Example of Western blot analysis using Mab LipL5. Lane 1, rLipL32; Lane 2, Australis; Lane 3, Autumnalis; Lane 4, Ballum; Lane 5, Brasiliensis; Lane 6, Canicola; Lane 7, Celledoni; Lane 8, Gripphotyphosa; Lane 9, Copenhageni; Lane 10, Icterohaemorrhagiae; Lane 11, Panama; Lane 12, Pomona; Lane 13, Patoc.

\section{Affinity Constants}

The six Mabs obtained in this study, together with a Mab (LipL1) from a previous fusion, ${ }^{[12]}$ were evaluated in the experiments of Ka determination. As shown in Table 2, MAb LipL1 was the one that demonstrated the highest affinity for rLipL32 and, as a consequence, the lower dissociation constant. The $\mathrm{Ka}$ is an important parameter affecting diagnostic tests since it gives information on the amount of antigen needed to saturate the antibody paratopes once the reaction reaches equilibrium, meaning that an antibody that saturates at a low antigen concentration is better suitable for diagnosis than an antibody that demands higher antigen concentrations. Here we have described the determination of the functional Ka which is the parameter better suited to be used in the evaluation of Mabs potential for use in ELISA. Leptospires are not normally abundant in the sera of infected patients since these bacteria have a transient phase in the blood ${ }^{[17]}$ thus, it is highly desirable that a Mab be capable not only to recognize pathogenic leptospires but also that it can detect a really low amount of the pathogen in the infected host Table 2.

Table 2. Affinity constants of MAbs against LipL32

\begin{tabular}{lc}
\hline Monoclonal Antibodies & Affinity Constant $\left(\mathrm{M}^{-1}\right)$ \\
\hline 1D9 & $5 \times 10^{7}$ \\
LipL2 & $9 \times 10^{6}$ \\
LipL3 & $3 \times 10^{7}$ \\
LipL4 & $3 \times 10^{7}$ \\
LipL5 & $6 \times 10^{6}$ \\
LipL6 & $2 \times 10^{7}$ \\
LipL7 & $2 \times 10^{7}$ \\
\hline
\end{tabular}


Table 3. Additivity index screening of MAbs against LipL32 by ELISA

\begin{tabular}{lrrrrrrr}
\hline Mabs & 1D9 & LipL2 & LipL3 & LipL4 & LipL5 & LipL6 & LipL7 \\
\hline 1D9 & - & 17.2 & 7.9 & 8.3 & 14.3 & 2.0 & 3.7 \\
LipL2 & 17.2 & - & 14.1 & 0.9 & 15.4 & 1.5 & 1.4 \\
LipL3 & 7.9 & 14.1 & - & 4.7 & 11.7 & 10.6 & 11.3 \\
LipL4 & 8.3 & 0.9 & 4.7 & - & 4.9 & 10.2 & 13.7 \\
LipL5 & 14.3 & 15.4 & 11.7 & 4.9 & - & 9.1 & 6.1 \\
LipL6 & 2.0 & 1.5 & 10.6 & 10.2 & 9.1 & - & 1.3 \\
LipL7 & 3.7 & 1.4 & 11.3 & 13.7 & 6.1 & 1.3 & - \\
\hline
\end{tabular}

Values are given in $\%$ for each pair of MAbs.

MAbs were used at a 1:400 dilution.

\section{Additivity Index}

Another experiment performed was the determination of the additivity index (AI), that groups the antibodies according to the region of the protein to which they react. The seven MAbs tested showed a really low additivity index when they were combined in the same well of the ELISA plate (Table 3), leading to the conclusion that they react either with the same epitope or with epitopes situated in regions of the protein molecule that binding of one Mab causes steric hindrance for other Mabs binding. The second alternative is probably true taking in account the relatively small molecular mass of LipL32.

\section{CONCLUSIONS}

In this work we reported on the production of six monoclonal antibodies that react with a linear epitope of both native and recombinant LipL32 which is the major outer membrane lipoprotein conserved in all leptospiral pathogenic sorovars. These MAbs were tested in experiments that can be very usefull in providing informations about desired characteristics that an antibody should have so it can be used as a reagent in a diagnostic test.

Our results have shown that the MAbs produced react with pathogenic leptospira from all serogroups tested and presented other characteristics that makes them suitable for development of novel diagnostic tests for leptospirosis.

\section{ACKNOWLEDGMENTS}

We are grateful to Dr. Claudiomar Soares Brod, from Centro de Controle de Zoonoses, for kindly providing Leptospira strains and to Dr. D. Haake from UCLA, Los Angeles, CA, for providing the protocol for LipL32 purification and for fruitful discussions. This work was supported by grants from Fundação Oswaldo Cruz (09224-7), Conselho Nacional de Desenvolvimento 
Científico e Tecnológico - CNPq (477609/2004-0,301920/2006-0 and 504227/2006-0) and National Institutes of Health, USA (AI034431 and TW00919).

\section{REFERENCES}

1. Faine, S.; Adler, B.; Bolin, C.; Perolat, P. Leptospira and Leptospirosis, 2nd Edn; MediSc: Melbourne, Australia, 1999, 272 pp.

2. Ko, A.I.; Galvao, R.M. Ribeiro Dourado, C.M.; Johnson, W.D., Jr.; Riley, L.W. Urban epidemic of severe leptospirosis in Brazil. Salvador Leptospirosis study Group. Lancet 1999, 354, 820-825.

3. Taylor, M.J.; Ellis, W.A.; Montgomery, J.M.; Yan, K.T.; McDowell, S.W.J.; Mackie, D.P. Magnetic immuno capture PCR assay (MIPA): detection of Leptospira borgpetersenii serovar hardjo. Vet. Microbiol. 1997, 56, 135-145.

4. Smits, H.L.; Eapen, C.K.; Sugathan, S.; Kuriakose, M.; Gasem, M.H.; Yersin, C.; Sasaki, D.; Pujianto, B.; Vestering, M.; Abdoel, T.H.; Gussenhoven, G.C. Lateralflow assay for rapid serodiagnosis of human leptospirosis. Clin. Diag. Lab. Immunol. 2001, 8, 166-169.

5. Eapen, C.K.; Sugathan, S.; Kuriakose, M.; Abdoel, T.; Smits, H.L. Evaluation of the clinical utility of rapid blood test for human leptospirosis. Diag. Microbiol. Infect. Dis. 2002, 42, 221-225.

6. Surujballi, O.; Elmgren, C. Monoclonal antibodies suitable for incorporation into a competitive enzyme-linked immunosorbent assay (ELISA) for the detection of specific antibodies to Leptospira interrogans serovar pomona. Vet. Microbiol. 2000, 71, 149-159.

7. Yan, K.T.; Ellis, W.A.; Mackie, D.P.; Taylor, M.J.; McDowell, S.W.J.; Montgomery, J.M. Development of an ELISA to detect antibodies to a protective lipopolysaccharide fraction of Leptospira borgpetersenii serovar hardjo in cattle. Vet. Microbiol. 1999, 69, 173-187.

8. Janeway, C.A.; Travers, P.; Walport, M.; Shlomchik, M. Immunobiology: The Immune System in Health and Disease, 5th Edn; Garland Publishing: New York, United States, 2001, 767 pp.

9. Haake, D.A.; Chao, G.; Zuerner, R.L.; Barnett, J.K.; Barnett, D.; Mazel, M.; Matsunaga, J.; Levett, P.N.; Bolin, C.A. The leptospiral major outer membrane protein LipL32 is a lipoprotein expressed during mammalian infection. Infect. Immun. 2000, 68, 2276-2285.

10. Bradford, M.M. A rapid and sensitive for the quantitation of microgram quantitites of protein utilizing the principle of protein-dye binding. Anal. Biochem. 1976, 72, 248-254.

11. Ramos, C.R.; Abreu, P.A.; Nascimento, A.L.; Ho, P.L. A high-copy T7 Escherichia coli expression vector for the production of recombinant proteins with a minimal N-terminal His-tagged fusion peptide. Brazilian J. Med. Biol. Res. 2004, 37, 1103-1109.

12. Lüdtke, C.B.; Coutinho, M.L.; Jouglard, S.D.D.; Moreira, C.N.; Fernandes, C.P.H.; Brod, C.S.; Haake, D.A.; KO, A.I.; Dellagostin, O.A.; Aleixo, J.A.G. Monoclonal antibodies against an outer membrane protein from pathogenic leptospira. Brazilian J. Microbiol. 2003, 34 (Suppl. 1), 1-4.

13. Laemmli, U.K. Cleavage of structural proteins during the assembly of the head of bacteriophage T4. Nature 1970, 227, 680-685. 
14. Friguet, B.; Chaffotte, A.F.; Djavadi-Ohaniance, L.; Goldberg, M.E. Measurements of the true affinity constant in a solution of antigen-antibody complexes by enzyme-linked immunosorbent assay. J. Immunol. Meth. 1985, 77, 305-319.

15. Bobrovnik, S.A. Determination of antibody affinity by ELISA. Theory. J. Biochem. Biophys. Meth. 2003, 57, 213-236.

16. Friguet, B.; Djavadi-Ohaniance, L.; Pages, J.; Bussard, A.; Goldberg, M.E. A convenient enzyme-linked immunosorbent assay for testing whether monoclonal antibodies recognize the same antigenic site. Application to hybridomas specific for the $\beta$-subunit of Escherichia coli tryptophan synthase. J. Immunol. Meth. 1983, 60, 351-358.

17. World Health Organization. Human Leptospirosis: Guidance for Diagnosis, Surveillance and Control; WHO Library: Malta, 2003, 122 pp.

Received October 16, 2006

Accepted November 23, 2006

Manuscript 3217 